Gut, 1986, 27, 784-788

\title{
A single night time dose of ranitidine in the acute treatment of gastric ulcer: a European multicentre trial
}

\author{
F P RYAN, R JORDE, R S B EHSANULLAH, K SUMMERS, AND J R WOOD \\ From the Northern General Hospital, Sheffield, University Hospital of Tromsoe, Tromsoe, Norway; Clinical \\ Research Division, Glaxo Pharmaceuticals Ltd., Greenford, Middlesex
}

\begin{abstract}
SUMMARY Four hundred and twenty eight patients with endoscopically diagnosed gastric ulcers, randomly allocated to treatment with ranitidine $300 \mathrm{mg}$ at night or ranitidine $150 \mathrm{mg}$ twice daily, were evaluated in a double blind multicentre trial conducted in 10 European countries. After four weeks, complete ulcer healing was observed in 138 of 211 patients (65\%) treated with ranitidine $300 \mathrm{mg}$ nocte and in 155 of 217 patients $(71 \%)$ receiving $150 \mathrm{mg}$ bd. Cumulative healing rates at eight weeks were $90 \%$ and $93 \%$, respectively. There was no statistically significant difference between the healing rates at either four or eight weeks. The treatment regimens were equally effective at rapidly reducing the incidence of ulcer related symptoms. Adverse events reported were minor and equally distributed between the two groups. The results of this trial show that $300 \mathrm{mg}$ of ranitidine administered at night is an effective and safe alternative to the current twice daily regimen for the short term treatment of gastric ulcer.
\end{abstract}

Controlled clinical trials in a large number of patients with peptic ulcer disease have shown that ranitidine in a dose of $150 \mathrm{mg}$ given twice daily is an effective and safe agent which promotes complete healing of the majority of peptic ulcers within four to eight weeks of treatment. ${ }^{1}$ Ranitidine $\left(\operatorname{Zantac}^{\circledR}\right)$ was introduced into clinical practice in 1981 and its extensive usage since then has confirmed the safety and efficacy of the drug.

Recent studies have shown that the same total daily dose $(300 \mathrm{mg})$ given at night is an effective and safe alternative to the standard twice daily regimen in the treatment of duodenal ulceration. ${ }^{23}$ In view of the established efficacy of ranitidine $150 \mathrm{mg}$ twice daily in the treatment of gastric ulcer, ${ }^{4}$ the above findings raise the possibility that a single daily dose of ranitidine may also have a place in the treatment of gastric ulcer. To evaluate this, the present trial compared the use of ranitidine $300 \mathrm{mg}$ at night with ranitidine $150 \mathrm{mg}$ bd in the treatment of gastric ulceration.

Address for correspondence: Dr F P Ryan, Northern General Hospital, Sheffield, S5 7AU.

Received for publication 14 October 1985.

\section{Methods}

PATIENTS

Five hundred and seventy one patients aged over 18 years with endoscopically diagnosed gastric ulcers were recruited into a double blind trial conducted in 96 centres in 10 European countries (Austria, Denmark, Holland, Ireland, Norway, Poland, Sweden, Switzerland, United Kingdom and West Germany), using a common protocol. Exclusion criteria comprised: ulcer perforation, upper gastrointestinal haemorrhage requiring transfusion during the previous week, pyloric stenosis, ZollingerEllison syndrome, concomitant use of potentially ulcerogenic drugs, peptic ulcer medication during the preceding 30 days (except for low dose antacids), pregnant and lactating women, liver disease, and other concurrent medical conditions. Patients with malignant changes found on histological examination of gastric biopsies were also excluded. Patients gave their informed consent to the study which was approved by ethics committees in individual countries. The trial was conducted in accordance with the Declaration of Helsinki, Tokyo Amendment, 1975.

Patients were randomly allocated to treatment 
with either ranitidine $300 \mathrm{mg}$ given as a single night time dose with a matching placebo in the morning or the conventional regimen of ranitidine $150 \mathrm{mg}$ twice daily. All tablets were identical in size and appearance. No other peptic ulcer treatment was permitted during the trial except for antacid tablets $\left(\right.$ Rennie $\left.^{\circledR}\right)$, with an acid neutralising capacity of $15.1 \mathrm{mmol}$, which were supplied for symptomatic relief.

Treatment was provided initially for four weeks, after which endoscopy was repeated and ulcer related symptoms assessed. Patients whose ulcers had not healed continued treatment for a further four weeks and were re-endoscoped and reassessed at the end of this period. At each visit, a physical examination was carried out and venous blood samples were taken for routine biochemical and haematological analyses. Biopsies of the ulcers were taken to exclude malignancy. Ulcer healing was defined as no break in the continuity of the mucosa with no exudate present as observed on endoscopy. Statistical analyses were carried out using the $\chi^{2}$ test (without continuity correction and following the Mantel-Haenszel method) and Student's $t$ test. Tests were considered to be significant if the $p$ value was less than the conventional $5 \%$ level.

Patients were included in the statistical analyses of ulcer healing rates if their second endoscopy was done within $28 \pm 4$ days of the beginning of the trial, and within $56 \pm 4$ days for those patients whose ulcers were unhealed at the time of the second endoscopy.

\section{Results}

One hundred and forty three patients entered into the trial were excluded from the analysis of healing rate at four weeks for reasons listed in Table 1. The distribution of exclusions was similar in the two treatment groups.

Of the 428 patients who were available for analysis at four weeks, 211 received ranitidine $300 \mathrm{mg}$ nocte and 217 received the twice daily

Table 1 Reasons for excluding patients from analysis

\begin{tabular}{lll}
\hline & \multicolumn{2}{l}{ Patients (no) } \\
\cline { 2 - 3 } & $\begin{array}{l}\text { Ranitidine } \\
\text { Reason }\end{array}$ & $\begin{array}{l}\text { Ranitidine } \\
150 \mathrm{mg} \text { bd }\end{array}$ \\
\hline No follow up endoscopy & 13 & 15 \\
Early/late endoscopy & 54 & 54 \\
Duodenal ulcer only & 1 & 2 \\
Adverse event & & 1 \\
$\quad$ necessitating withdrawal & 3 & 72 \\
Total & 71 & \\
\hline
\end{tabular}

regimen. The two treatment groups were comparable with respect to patient sex, age, weight, smoking habits, alcohol consumption, duration of dyspeptic history and current episode, and evidence of haematemesis/melaena (Table 2).

\section{ULCER HEALING}

After four weeks, complete gastric ulcer healing was observed in 138 out of 211 patients $(65 \%)$ in the $300 \mathrm{mg}$ nocte group and in 155 of 217 patients $(71 \%)$ in the $150 \mathrm{mg}$ bd group. At eight weeks, the cumulative healing rates were $90 \%$ (176 of 196 patients) and $93 \%$ (189 of 204 patients), respectively. There were no statistically significant differences between the healing rates in the two groups at either four $(p=0 \cdot 18)$ or eight weeks $(p=0 \cdot 31)$.

There was no evidence that the healing rate at either four or eight weeks was influenced by patient sex, smoking habits or alcohol consumption (Table 3 ) or that it differed for single or multiple ulcers. Although healing rates varied from country to country, no statistically significant differences were observed at four or eight weeks between the two treatment groups in the individual countries.

\section{ULCER RELATED SYMPTOMS}

The degree of severity and incidence of ulcer related symptoms (epigastric pain, heartburn, nausea and vomiting) were found to be similar in the two

Table 2 Demographic background of population

\begin{tabular}{|c|c|c|}
\hline & $\begin{array}{l}\text { Ranitidine } \\
300 \mathrm{mg} \text { nocte }\end{array}$ & $\begin{array}{l}\text { Ranitidine } \\
150 \mathrm{mg} \mathrm{bd}\end{array}$ \\
\hline Patients (No) & 211 & 217 \\
\hline $\operatorname{Sex}(M: F)$ & $116: 95$ & $119: 98$ \\
\hline Age $(y r):$ mean $\pm S D$ & $55 \pm 14$ & $56 \pm 15$ \\
\hline Weight $(\mathrm{kg})$ : mean $\pm \mathrm{SD}$ & $67 \pm 14$ & $66 \pm 15$ \\
\hline \multicolumn{3}{|l|}{ Smoking status: } \\
\hline None & 82 & 94 \\
\hline Light & 96 & 85 \\
\hline Heavy & 33 & 38 \\
\hline \multicolumn{3}{|l|}{ Alcohol intake: } \\
\hline None & 120 & 121 \\
\hline$<20 z /$ day & 82 & 87 \\
\hline$\geqslant 2 \mathrm{oz} /$ day & 8 & 8 \\
\hline Unspecified & 1 & 1 \\
\hline \multicolumn{3}{|l|}{ Duration of dyspeptic } \\
\hline history (yr): Median & 3 & 4 \\
\hline Interquartile range & $1-8$ & $1-10$ \\
\hline \multicolumn{3}{|l|}{ Duration of current } \\
\hline episode (mth): Median & 2 & 2 \\
\hline Interquartile range & $1-3$ & $1-3$ \\
\hline \multicolumn{3}{|l|}{$\begin{array}{l}\text { Evidence of haematemesis/ } \\
\text { melaena: }\end{array}$} \\
\hline Yes & 38 & 31 \\
\hline No & 172 & 186 \\
\hline Unspecified & 1 & 0 \\
\hline
\end{tabular}


Table 3 Healing rates randomised for smoking and alcohol intake

\begin{tabular}{lcc}
\hline & $\begin{array}{l}\text { Ranitidine } \\
300 \mathrm{mg} \text { nocte }\end{array}$ & $\begin{array}{l}\text { Ranitidine } \\
150 \mathrm{mg} \text { bd }\end{array}$ \\
\hline $\begin{array}{l}\text { Four weeks } \\
\quad \text { Non-smokers }\end{array}$ & $57 / 82(70 \%)$ & $68 / 94(72 \%)$ \\
$\quad$ Smokers & $81 / 129(63 \%)$ & $87 / 123(71 \%)$ \\
Eight weeks & $68 / 78(87 \%)$ & $80 / 89(90 \%)$ \\
$\quad$ Non-smokers & $108 / 118(92 \%)$ & $109 / 115(95 \%)$ \\
$\quad$ Smokers & $81 / 120(67 \%)$ & $86 / 121(71 \%)$ \\
Four weeks & $57 / 90(63 \%)$ & $68 / 95 \quad(72 \%)$ \\
$\quad$ No alcohol & & $103 / 113(91 \%)$ \\
$\quad$ Alcohol consumers & $101 / 111(91 \%)$ & $85 / 90 \quad(94 \%)$ \\
Eight weeks & $75 / 85(88 \%)$ & \\
$\quad$ No alcohol & & \\
$\quad$ Alcohol consumers & & \\
\hline
\end{tabular}

treatment groups at the pretrial, four, and eight week visits. Both treatment regimens were equally effective at rapidly reducing the incidence of these symptoms.

\section{COMPLIANCE}

Test tablet compliance and antacid consumption were assessed by returned tablet counts at the end of the four week treatment period. Treatment compliance and antacid consumption were similar in the two groups. The compliance was excellent in both treatment groups, and the average daily consumption of antacid tablets was 0.4 and 0.5 in the $300 \mathrm{mg}$ nocte and $150 \mathrm{mg}$ bd groups, respectively.

\section{CARDIOVASCULAR PARAMETERS}

There were no statistically significant differences between the two treatment groups at either four or eight weeks with respect to systolic or diastolic blood pressure or pulse rate.

BIOCHEMICAL AND HAEMATOLOGICAL ANALYSES All 571 patients who entered the trial were screened for abnormalities in the laboratory parameters determined. Modest and transient increases in some laboratory values which were considered to be possibly drug related were observed in three out of 211 patients receiving ranitidine $300 \mathrm{mg}$ nocte and in four out of 217 patients receiving ranitidine $150 \mathrm{mg}$ bd. One 86 year old woman showed raised urea (4 to $14.4 \mathrm{mmol} / \mathrm{l}$, normal range $2 \cdot 5-7 \cdot 5$ $\mathrm{mmol} / \mathrm{l})$ and creatinine (60 to $180 \mu \mathrm{mol} / \mathrm{l}$, normal range 53-115 $\mu \mathrm{mol} / \mathrm{l})$ and one 74 year old woman was found to have a raised GGT (12 to $94 \mathrm{IU} / \mathrm{l}$, normal range 7-33 IU/l) after four weeks treatment with ranitidine $150 \mathrm{mg}$ bd. The remaining five patients exhibited small rises in SGPT or SGOT to just outside the normal ranges at four weeks of therapy.

\section{ADVERSE EVENTS}

A total of 18 adverse events were reported by 15 patients; eight patients $(3 \%)$ receiving ranitidine $300 \mathrm{mg}$ nocte and seven patients $(2 \%)$ receiving $150 \mathrm{mg}$ bd. The distribution of adverse events (Table 4) was comparable for the two treatment groups. No deaths were reported during the trial. Five patients, three in the nocte group and two in the bd group (one during the second treatment period), withdrew from the study because of adverse events. None of the events reported was serious or unexpected, and in none of the cases was a causal relationship with ranitidine considered to be likely.

\section{Discussion}

The results of this trial show that a single nocturnal dose of ranitidine $300 \mathrm{mg}$ is as effective as the conventional $150 \mathrm{mg}$ twice daily regimen in the acute healing of gastric ulcer. Ulcer healing rates assessed after four or eight weeks of treatment were not statistically significantly different in a patient population sufficiently large to enable the detection of a $15 \%$ difference with a $90 \%$ confidence. The majority of patients $(90 \%$ or more) showed complete ulcer healing after eight weeks' therapy. The healing rates for the twice daily regimen are similar to those reported previously in trials comparing it with either placebo or other active drugs. ${ }^{6}{ }^{5}$ Gastric ulcer healing in both treatment groups was found to be independent of patient sex, smoking habits and alcohol consumption. The latter results confirm previous findings of Kellow and others ${ }^{8}$ that smoking and alcohol intake did not influence the effect of ranitidine on gastric ulcer healing.

The incidence and severity of epigastric pain and other dyspeptic symptoms were rapidly reduced by

Table 4 Adverse events

\begin{tabular}{lll}
\hline & Reports (no) $($ No withdrawn) \\
\cline { 2 - 3 } & $\begin{array}{l}\text { Ranitidine } \\
300 \mathrm{mg} \text { nocte } \\
(n=282)\end{array}$ & $\begin{array}{l}\text { Ranitidine } \\
150 \mathrm{mg} \text { bd. } \\
(n=289)\end{array}$ \\
& & \\
\hline Diarrhoea/constipation & 0 & $3(0)$ \\
Epigastric pain & 0 & $1(1)$ \\
Headache & $2(1)$ & 0 \\
Fatigue & $2(1)$ & $2(0)$ \\
Dizziness & $1(0)$ & 0 \\
Skin rash & $2(1)$ & $2(1)$ \\
Gynaecomastia & $1(0)$ & 0 \\
Chest pain & $1(1)$ & $1(1)$ \\
Total & $9(4)$ & $9(3)$ \\
Patients (No) & $8(3)$ & $2(0 \cdot 7)$ \\
Total population $(\%)$ & $3(1)$ & \\
\hline
\end{tabular}


both treatment regimens and antacid consumption was similar in the two groups. Compliance was good for both treatment regimens.

Clinical trials evaluating the effect of once daily ranitidine $(300 \mathrm{mg}$ at night) in the treatment of duodenal ulcer have shown that this regimen is equivalent to the standard $150 \mathrm{mg}$ bd regimen in terms of ulcer healing. These findings have been taken as support for the hypothesis that nocturnal secretion of acid is of particular importance in the pathogenesis of duodenal ulcer. Nocturnal acid secretion in gastic ulcer disease is known to be normal or reduced. ${ }^{910}$ In view of this, the present findings suggest that the equivalence of once and twice a day ranitidine therapy for acute healing of peptic ulcer may result from comparable reductions in 24 hour gastric acidity by the two regimens rather than an effect due to nocturnal administration per se. Whilst studies have compared the effects of $150 \mathrm{mg}$ bd and $300 \mathrm{mg}$ nocte on 24 hour gastric acid secretion in duodenal ulcer and shown them to reduce gastric acidity to a comparable extent, similar studies have yet to be reported for gastric ulcer.

A recent study comparing gastric ulcer healing with ranitidine and omeprazole, an extremely potent inhibitor of gastric acid secretion, ${ }^{11}$ reported healing rates of 45,80 and $90 \%$ for ranitidine and 43,81 and $95 \%$ for omeprazole after two, four and eight weeks, respectively, with no statistically significant difference between the two drugs at any time interval. ${ }^{12}$ These results indicate that, in contrast with findings in patients with duodenal ulcer, ${ }^{13}$ suppression of gastric acidity to a greater extent than that achieved by the present two ranitidine regimens is unlikely to result in more rapid ulcer healing.

The absence of serious or unexpected adverse events in both treatment groups, and the lack of clinically significant biochemical or haematological changes during a treatment for up to eight weeks confirm that ranitidine, whether given in the conventional twice daily regimen or as a single night time dose, is a well tolerated and safe drug for the treatment of acute gastric ulceration. The single night-time dose may improve treatment compliance for certain patients.

We are grateful to the following gastroenterologists who participated in this trial:

\section{PARTICIPATING INVESTIGATORS}

Austria

Dr H Brunner. Dr G Judmaier. Dr E Kerstan/Dr H Thaler. Dr W Weiss

Denmark

Dr L Banke, Dr P Bech-Jansen, Prof P M Christiansen, Dr B Clausen, Dr P Funch-Jensen, Dr P M Joergensen. Dr H E R Lange, Dr H Marcussen. Dr F Moesgaard, Dr J G Stage
Holland

Dr C P Dekkers, Dr F M Lalisang. Dr W W Meijer, Dr P M DeVries, Dr G F Nelis, Dr P Pop

Ireland

Dr G J Burke, Prof J S Doyle, Dr J Lennon/Dr J Crowe, Dr D P O’Donoghue, Dr T O'Gorman. Dr M J Whelton

Norway

Dr O Dahlberg. Dr N Hovdenak, Dr L Hval, Dr O B Karlsen, Dr R Jorde. Dr K Nordgaard, Dr M Toender

Poland

Prof E: Butruk. Dr J Gil, Prof A Gabryelewicz, Prof J Hasik. Dr A Nowak. Prof J Pokora

Sweden

Dr I. Fnskog. Dr U Haglund, Dr J Hedenbro, Dr M Hradsky. Dr J Lindhagen. Dr A Norrby/Dr B Jaup. Dr J Oscarson. Dr G Simert, Dr B Stenquist

Switzerland

Dr J Altdorfer. Dr H Buhler. Dr W H Hacki. Dr W Woodtli $U K$

Dr A T R Axon. Dr A D Beattic. Dr E R Beck. Dr G (; Birnic. Dr S N Booth. Dr M ( B Bramble, Dr W R Burnham. Dr H A Carmichacl. Dr R Cockel. Dr B J Collins, Dr M E Denyer. Dr E Elias, Dr P D Fairclough. Dr J M Findlay, Dr J A Gibson, Dr W Hislop. Dr G D Kerr, Mr R D Kingston, Dr N Krasner. Dr R J McFarland. Dr G Neale. Dr F A ( ) Connor. Dr R T Orchard. Dr C Patel. Dr A J G Pearson. Dr K G Porter. Dr W D W Rees. Dr F P Ryan. Dr P R Salmon. Dr J M Temperley. Dr W O Thomson. Dr G Tildesley, Dr R J Utley. Dr T W Warnes

West Germany

Dr H Brinkhoff. Prof (; Brunner, Dr F Gierthmuhlen, Dr H Hebbeln. Dr W Huttemann. Dr K (i Jensen. Dr W Panijel, Dr H G Rohner. Prof L Safrany. Dr F Tympner

\section{References}

1 Meyrick Thomas J, Misiewicz JJ. Histamine $\mathrm{H}_{2-}$ receptor antagonists in the short- and long-term treatment of duodenal ulcer. Clin Gastroenterol 1984; 13: 501-41.

2 Ireland A, Colin-Jones DG, Gear P et al. Ranitidine $150 \mathrm{mg}$ twice daily vs $300 \mathrm{mg}$ nightly in treatment of duodenal ulcers. Lancet 1984; 2: 274-6.

3 Brackmann HP, Brinkhoff H, Dammann HG et al. Akutbehandlung der ulkus-duodeni-erkrankung mit ranitidine. Therapiewoche 1984; 34: 5232-7.

4 Kelly KA, Malagelada J-R. Medical and surgical treatment of chronic gastric ulcer. Clin Gastroenterol 1984; 13: 621-34.

5 Ryan FP. A comparison of ranitidine and placebo in the acute treatment of gastric ulcer. In: Misiewicz JJ and Wormsley KG, eds. The clinical use of ranitidine; Proceedings of the second international symposium on ranitidine. Oxford: Medicine Publishing Foundation, 1982: 201-5.

6 Baron JH, Perrin VL. Gastric ulcer healing with ranitidine and cimetidine. A multicentre study. Scand J Gastroenterol 1983; 18: 973-6.

7 The Belgian Peptic Ulcer Study Group. Single blind comparative study of ranitidine and cimetidine in patients with gastric ulcer. Gut 1984; 25: 999-10)(2.

8 Kellow JE, Barr GD, Cowen AE, Ward M, Wood L, Piper DW. Comparison of ranitidine and cimetidine in the treatment of chronic gastric ulcer. Digestion 1983; 27: $105-10$.

9 Johnson HD. The classification and principles of treatment of gastric ulcers. Lancet 1957; 2: 518-20.

10 Baron JH. Gastric ulcer and carcinoma. In: Baron JH, 
ed. Clinical tests of gastric secretion, London: The Macmillan Press Ltd. 1978; 86-97.

11 Sharma BK, Walt RP, Pounder RE, Gomes M De FA, Wood EC, Logan LH. Optimal dose of oral omeprazole for maximal 24 hour decrease of intragastric acidity. Gut 1984; 25: 957-64.

12 Classen M, Dammann HG, Domschke W et al. Healing rate of gastric ulcer after treatment with omeprazole or ranitidine: results of a German multicentre trial. Dtsch Med Wochenschr 1985; 110: 628-33.

13 Classen M, Dammann HG, Domschke W et al. Short-duration treatment of duodenal ulcer with omeprazole and ranitidine: results of a multicentre trial in Germany. Dtsch Med Wochenschr 1985; 110: 210-15. 